\title{
Educação para a \\ comunicação social: \\ experiências educativas \\ com o jornalismo em \\ Portugal, por Manuel Pinto
}

\author{
Maria Rehder \\ Vice-presidente da Associação Brasileira de Pesquisadores e Profissionais em Educomunicação \\ (ABPEducom) e pesquisadora do Núcleo de Comunicação e Educação da Universidade de São \\ Paulo (NCE-USP). Mestre em Direitos Humanos e Democratização pela Università di Padova \\ (Eiuc) e especialista em Gestão da Comunicação pela Escola de Comunicações e Artes (ECA-USP). \\ E-mail: maria.rehdersp@gmail.com \\ Felipe Saldanha \\ Doutorando em Ciências da Comunicação pela Universidade de São Paulo (USP). Mestre em \\ Tecnologias, Comunicação e Educação pela Universidade Federal de Uberlândia (UFU). \\ E-mail: fgsaldanha@gmail.com
}

Resumo: O diretor do Doutoramento em Ciências da Comunicação da Universidade do Minho (Portugal) e membro do Centro de Estudos de Comunicação e Sociedade (Cecs), professor Manuel Joaquim Silva Pinto, concedeu entrevista exclusiva à revista Comunicação \& Educação na ocasião de sua vinda ao Brasil. Manuel Pinto conta o que o motivou a ingressar na área da educação para a comunicação social. Também falou sobre os resultados de suas pesquisas acerca do papel do jornalismo nesse campo e destacou a importância de olhar para as crianças não apenas como filhos ou alunos, mas como sujeitos que têm os direitos de expressão e participação assegurados.

Palavras-chave: alfabetização midiática; educação para a comunicação social; educação para os media; educomunicação; jornalismo na educação.
Abstract: The Dean of the Doctoral Program in Communication Sciences of the University of Minho (Portugal) and member of the Center for Communication and Society Studies (Cecs), Professor Manuel Joaquim Silva Pinto, gave an exclusive interview to Comunicação \& Educação journal in the occasion of his visit to Brazil. Manuel Pinto tells us what motivated his entrance into the field of Education for Social Communication. He also addressed the results of his researches about the role of journalism in this area and stressed the importance of looking at children not only as sons and daughters or students, but as subjects who have their own rights of expression and participation.

Keywords: media literacy; education for social communication; media education; educommunication; journalism in education. 
Manuel Joaquim Silva Pinto, diretor do Doutoramento em Ciências da Comunicação da Universidade do Minho, em Braga, Portugal, e membro do Centro de Estudos de Comunicação e Sociedade (Cecs), veio ao Brasil, especialmente a convite do Núcleo de Comunicação e Educação da Universidade de São Paulo (NCE-USP) e da Associação Brasileira de Pesquisadores e Profissionais em Educomunicação (ABPEducom), para integrar a mesa "Inovação e protagonismo social, na educação midiática" do II Congresso Internacional de Comunicação e Educação e VIII Encontro Brasileiro de Educomunicação, realizado em novembro de 2018, na Escola de Comunicações e Artes (ECA-USP), em São Paulo.

O professor, também membro do Grupo Informal sobre Literacia Mediática (GILM), que reúne oito entidades públicas portuguesas ligadas aos setores de comunicação, educação e ciência, é um dos grandes nomes europeus dos estudos de literacia para os media e de educação para a comunicação social. $\mathrm{Na}$ ocasião de sua vinda ao Brasil, o professor concedeu entrevista exclusiva à revista Comunicação $\mathcal{E}$ Educação, compartilhando sua trajetória acadêmica e profissional e falando sobre o papel do jornalismo na alfabetização midiática, bem como da importância da educação para as audiências.

Durante a conversa, Manuel Pinto relatou como foi o começo de sua vida acadêmica durante a ditadura salazarista em Portugal e falou sobre a opção por cursar História, pois, à época, os cursos de Ciências Sociais e Comunicação haviam sido banidos no país, só voltando após a Revolução dos Cravos, que depôs o regime ditatorial do Estado Novo em 25 de abril de 1974. Contou também como ingressou no campo da educação para a comunicação social, destacou a importância dos direitos de expressão e comunicação garantidos às crianças e refletiu sobre os desafios do jornalismo diante de um mundo no qual é difícil produzir sentidos em meio ao excesso de informação.

\section{Comunicação $\mathcal{E} \mathcal{E}^{2}$ Educação: Professor, gostaríamos que o senhor falasse sobre sua trajetória acadêmica até voltar seu interesse para as áreas da comunicação e da educação. \\ Manuel Pinto: Eu tive uma trajetória que foi muito resultante de circuns-} tâncias da vida. Quando terminei o meu estudo secundário [equivalente ao ensino médio no Brasil], fui me inscrever em História pois não havia estudos de Comunicação Social no ensino superior, porque Salazar ${ }^{1}$ e a ditadura de alguma forma baniram os estudos de Ciências Sociais da universidade, incluindo, é claro, os estudos de Jornalismo e de Comunicação. Portanto só depois de 25 de abril [de $1974^{2}$ ], e alguns anos depois, tivemos o primeiro curso.

Quando eu comecei, em meados dos anos 1970, como não havia o curso, para mim era muito claro [escolher] História, porque eu havia tido uma excelente experiência como professor no Liceu, que me abriu bastante os horizontes, e fiquei entusiasmado pelo conhecimento histórico. Mas, curiosamente, acabei História e [comecei] a gostar de Antropologia, precisamente porque sempre tive

1. António Salazar foi chefe de um regime ditatorial em Portugal entre 1932 e 1968.

2. Data da Revolução dos Cravos, que depôs o regime ditatorial do Estado Novo. um interesse muito grande pela cultura popular tradicional. De resto, acabei por ir para o Jornalismo porque imaginei que fosse um sítio favorável para ver hipóteses de emprego no âmbito da Antropologia, o que não aconteceu, pois minha vida foi respondendo às solicitações e às circunstâncias. 
O que aconteceu foi que, rapidamente, num jornal diário, concorremos 427 pessoas para 12 vagas, num tempo em que ainda havia concursos para vagas no Jornalismo - isso é uma figura da história há muitos anos já, infelizmente -, e eu creio que entrei não porque tivesse qualquer formação no Jornalismo, mas porque dirigi uma revista de pensamento e de intervenção enquanto estudante do ensino superior. E isso pesou. Eu só vim a saber [disso] depois pelos jornalistas que apreciaram as candidaturas. $\mathrm{O}$ que aconteceu foi que eu me tornei também editor de educação nesse diário, depois de dois ou três anos, e mantive esse cargo até o fim. Nesse trabalho eu rapidamente percebi, primeiramente: a importância da educação no jornalismo; e em segundo lugar: a importância da educação para as audiências. Isso porque muitas vezes, no ritmo exigido para trabalhar num jornal diário, eu tinha a consciência de que o trabalho preparado para o "buraco" lá reservado, para mim e minha equipe, não estava bem feito. Eu gostava que ele fosse bem feito. E no entanto era raro, muito raro, haver reações da parte do público.

Um dia, em outra função, estava em Paris, na Organização das Nações Unidas para a Educação, a Ciência e a Cultura (Unesco), à espera de ser recebido por alguém, e lá estava uma secretária com quem eu comecei a falar. Ela perguntou-me se eu gostava de ser jornalista, e eu respondi que sim, mas tinha essa questão de não saber como se resolvia o problema de, de alguma forma, tornar as audiências mais interventivas. E ela me disse: "Mas isso é educação para os media". Eu lhe perguntei: "E o que é isso?". Ela respondeu: "Ah, não sabe? Olha cá, temos estes dois livros que descrevem experiências em todo o mundo. Se quiser, eu te ofereço”. E aquilo foi uma revelação para mim. De repente vi que havia todo um continente a jusante do meu trabalho, a jusante da mídia, daquele veículo em concreto que eu nunca tinha visto. Eu via aquela gente como os destinatários do que nós estávamos a fazer, e não propriamente como um terreno que se podia cultivar. Para falarmos em termos de agricultura: podia-se cultivar aquele terreno, podia-se desenvolver competências, podia-se fazer trabalhos pedagógicos no sentido de tornar esse encontro com a informação um encontro mais inteligente, interventivo e também capacitador.

Ora, nesse cenário, aconteceu uma coisa muito interessante. A Associação dos Editores de Jornais Portugueses, preocupada com o decréscimo da audiência de jornais, lançou uma campanha nacional intitulada "Ler jornais é saber mais”. E fez vários jornalistas irem às escolas para sensibilizar os professores e os alunos sobre a importância de ler jornais e de incorporá-los na escola. $\mathrm{Eu}$ apercebi-me de que isso ia ao encontro da dica ou do input que eu havia recebido na Unesco e de que poderia ser feito um trabalho com os jornais e por que não? - com os outros meios também. A partir de então comecei a me dedicar a estudar o que se poderia fazer com base nessa literatura, por meio dela e das referências bibliográficas. Eu não tive logo acesso a muitas publicações, mas escrevi para endereços que nelas vinham, dizendo: "Olha, aqui não há nada. Se vocês tiverem materiais que me ajudem, mandem”. E comecei a receber [publicações] pelo correio, porque àquela altura não havia internet, nada disso. Tínhamos que escrever cartas, pôr selos, escrever, daí esperar um mês 
de quem tivesse sido sensível. E devo dizer que foi impressionante a resposta que eu tive. Então comecei de fato a ver que havia ali um campo de trabalho.

Nesse contexto, fui convidado a integrar a Comissão de Reforma do Sistema Educativo nacional. Houve ali um governo que tomou essa iniciativa e meteram-me lá, penso que pelo fato ser um jornalista - alguém que tivesse um pouco desse lado comunicacional para noticiar a reforma à sociedade. Então achei que eu poderia introduzir nesse trabalho a dimensão da "educação para os media", como nós chamávamos, que é a tradução da expressão francesa "éducation aux médias", ou "media education", para os ingleses. Começamos a dizer assim porque consideramos que a "educação para" é o processo pedagógico, e a literacia é o uso dessas competências - capacidade que é naturalmente desigual na sociedade, o que a diferencia de muitos outros fatores. E pronto. Nesse contexto da Comissão de Reforma do Sistema Educativo Nacional estava o reitor da Universidade do Minho, que disse: "Seria interessante essa perspectiva nos cursos de formação de professores e de educadores da universidade".

E assim me convidaram para ir à universidade. Eu deixei o jornalismo, comecei um trabalho em 1988 - portanto, há 30 anos - e, hoje, uma das minhas principais colaboradoras foi aluna da primeira turma que eu tive em Educação para os Media. Já agora, deram-me a oportunidade de batizar a criança que estava a nascer na universidade, e eu chamei-a de "Educação para a Comunicação Social", e não de "Educação para os Media", porque achei que esse termo não era significativo, quer para as escolas e as estruturas da universidade, quer para a sociedade em geral; enquanto o conceito de educação para a comunicação social estava relativamente estabelecido em um significado que não admitia grandes dúvidas, pois se referia à mídia em geral. Havia também outra razão: um livro da Unesco, de autoria do professor James Halloran, da Universidade de Leicester, defendia que toda a educação para os media deveria ser, antes de mais nada, uma educação para a comunicação - e mantenho sempre essa ideia.

E mais: hoje nós enfatizamos tanto o lado midiático nessa tradição de media e educação que acho que precisamos voltar a chamar, amarrar e convocar para o nosso terreno a dimensão comunicacional, e não apenas midiática, porque esta alimenta um grande equívoco em torno do nosso trabalho, que é o de reduzir - mesmo que não o façamos ou que outros não interpretem assim - tudo a uma perspectiva instrumental e tecnológica, ou seja, de uso das ferramentas e dos veículos para ou na educação. Ora, isso é sobretudo educar para fazer dos media um tema de estudo, análise e intervenção - de várias maneiras e vertentes - não apenas nos conteúdos, mas nas instituições que estão por detrás, nos profissionais que desenvolvem e põem em ação as suas competências, nas tecnologias que são utilizadas, nos conteúdos produzidos, nos gêneros, nas programações e, obviamente, nas audiências e nos públicos, que são um fator absolutamente crucial para percebermos tudo isso. Isso é, de forma muito rápida, um pouco do programa desenhado para Educação para os Media. Foi assim que eu entrei nesse mundo, e aqui estou ainda a aprender.

$C \mathcal{E}{ }^{2} E$ : O senhor escreveu sobre o papel da indústria jornalística na alfabetização midiática. Então gostaríamos de saber qual seria esse papel e se ele tem sido 
desempenhado. Fique à vontade também para falar sobre a função do jornalismo na educação para a comunicação social, se fôssemos ampliar a noção do tema.

MP: Esse tópico foi suscitado por um trabalho feito com uma estudante de pós-doutoramento que trabalhou comigo até o ano passado [2017] sobre essa questão, Maria José Brites. Esse tema surge da percepção de que não podemos falar sobre uma literacia das notícias ou em torno do jornalismo sem convocar também para a conversa - se pudermos falar assim - os editores e as empresas que produzem jornalismo. Nós poderíamos considerar apenas os jornalistas, mas sabemos que estes não têm uma autonomia total - hoje têm, aliás, pouquíssima autonomia -, porque há uma pressão muito forte dos editores e dos diretores no sentido de fazer o jornalismo corresponder ao projeto editorial tal como eles o entendem e, sobretudo, satisfazer as audiências. Isso, às vezes, condiciona e baliza de forma redutora o trabalho dos jornalistas.

Então, nós quisemos interrogar diretores de jornais, editores e chefes de redação para perceber como eles próprios viam a sua responsabilidade no trabalho que faziam enquanto instituição, ou seja, se tinham uma percepção de que lhes cabia alguma parte de responsabilidade num desafio que toda a gente reconhece que é importante, no sentido de que as pessoas saibam ler criticamente e inteligentemente a informação e, com isso, adquiram capacidades de leitura do mundo, mesmo no sentido freiriano. Portanto, nossa conclusão foi de que o quadro apurado [em relação aos dirigentes de jornais] não é de uma pobreza franciscana, porque é verdade que há alguma percepção de que deveriam fazer alguma coisa, mas depois eles se curvam ao ritmo do trabalho, à pouca gente, à redução das redações, que foi arrasadora na última década, e à falta de experiência - porque muitas vezes desfizeram-se dos veteranos, aqueles que tinham o saber mais apurado, e ficaram com um corpo muito mais jovem, que ainda precisa fazer certo percurso. Assim, o que procuramos evidenciar com essa investigação - que deu origem a um artigo publicado no Reino Unido ${ }^{3}$ - foi que [o jornalismo] é uma frente de trabalho que não podemos desprezar, na qual há algumas virtualidades e sensibilidades, e que precisamos, se calhar, nos juntar à volta da mesa para ver como podemos nos ajudar uns aos outros, para que daí saia alguma ação.

$C \mathcal{E} E$ : Professor, além do jornalismo, o seu currículo de pesquisador trata de alguns outros temas, como a sua experiência no Centro de Estudos de Comunicação e Sociedade, envolvendo também a pesquisa sobre alfabetização midiática e TV, videojogos, internet e redes. Quais aspectos principais dessa pesquisa o senhor poderia relatar?

MP: Transversal a isso tudo é uma preocupação que vem da minha tese de doutoramento sobre a televisão no cotidiano das crianças, feita nos anos 1990 um contexto completamente diferente dos dias de hoje. $\mathrm{O}$ ano em que entreguei minha tese, 1995, foi quando surgiu de rompante a internet. Fiz um curso na minha universidade sobre o que é a internet e, quando eu vi o que ali estava desenhado, pensei: "Eu andei a gastar três anos e meio da minha vida para nada. Daqui a meia dúzia de anos, a televisão já não existe, porque isso é uma coisa perfeitamente revolucionária”. Bom, a vida depois nos ensina a ser mais calmos e comedidos nos juízos, porque hoje vemos que, apesar de a situação ter se alterado radicalmente, a

3. BRITES, Maria José; PINTO, Manuel. Is there a role for the news industry in improving news literacy? Media Education Research Journal, Leighton Buzzard, v. 7, n. 2, p. 29-47, 2017. 
televisão tem ainda uma centralidade enorme na estruturação do tempo e mesmo nos consumos em geral. A linha forte que buscamos desenvolver na Universidade do Minho foi esta: procurar evidenciar que não podemos nos limitar às jovens gerações na sua relação com a mídia, centrando-nos apenas na questão mais óbvia e do senso comum, que é "o que a mídia faz às crianças e aos mais novos?", "que influência tem, para o bem ou para o mal?”, "qual é o seu impacto na sociedade, e em particular nos mais jovens?”. É ver o que os mais novos fazem com a mídia. É nos pôr num outro ponto de vista e escutar a palavra dos jovens e das crianças, ouvindo não apenas o que eles têm a dizer, mas os quadros em que eles o dizem.

Eu contei um pequeno episódio no Congresso [II Congresso Internacional de Comunicação e Educação] que vale a pena ser contado aqui também. Eu quis ouvir as crianças e organizei vários grupos focais, em contextos sociais diferentes, sem dizer que o que me preocupava era a televisão. Eu dizia que o que me preocupava era o que as crianças faziam quando não estavam na escola. Quando eu colocava essa questão, eles começavam a falar das imensas coisas que faziam: muitas atividades. Algumas delas até me metiam certo medo porque eram completamente organizadas pelos pais para que elas seguissem vida afora e fossem uns "yuppies" cheios de sucesso na vida - à frente dos outros se possível, passando por cima deles. Mas não só: havia de fato uma diversidade grande até de jogos ou brincadeiras, e a televisão não apareceu. Eu achava aquilo espetacular. Como é que ninguém tomava a iniciativa de falar da televisão? Então, em determinado momento, eu cortava e falava: "Estou espantado com uma coisa. Os outros meninos com quem falei diziam-me uma coisa que faziam e que ninguém aqui faz, que é ver televisão". Apenas eu tocava nesse tema e se armava um fuzuê: "Todos nós vemos, e muito". E então eu dizia: "Por que não se referiram a isto?". "Porque o professor disse 'atividades', e ver televisão não é uma atividade”. E eu vi, de repente, que o meu mundo estava completamente de pernas para o ar, porque eu colocava o meu objetivo, aquilo que eu queria ver, formatava-o e criava um framing, como se fosse uma atividade na qual não cabia aquilo que eu queria ver. Apenas quando eu abria o meu framing, eles imediatamente descreviam a sua experiência, mas diziam que aquilo não era atividade porque nós não dissemos que comíamos, por exemplo, nem que bebíamos, nem que respirávamos, nem que íamos e vínhamos da escola. Daí eu disse: "Tá certo. Eu é que estou errado. Eu é que tenho que refazer todo o meu esquema daquilo tudo que eu tinha formatado". Tudo em volta do conceito de atividade eu tive de pôr em outra posição e começar a olhar o problema a partir dos termos que eles colocavam.

$\mathrm{Eu}$ creio que isso que me aconteceu é transversal a toda a experiência midiática dos jogos, dos tablets, da internet, seja o que for. Depois desenvolvemos outros estudos em que já nos colocamos um bocado nessa perspectiva. É aquilo que eu coloco de mais saliente, porque vem ao encontro do movimento cultural e político, até, que é o de reconhecer o direito da criança de dizer o mundo em seus próprios termos e de ser ouvida nesses termos, e não naqueles que nós impomos. Nós deveríamos olhar para elas não como alunos, mas como pessoas; não como filhos, mas como pessoas que moram nos filhos; não como consumidores, mas pessoas que moram nos consumidores. Nós tendemos, em 
nossa vida social, a olhar as pessoas por um estatuto determinado, que nos interessa ver, e depois temos dificuldade em ver que há uma pessoa ali, que é sujeito de direitos. As crianças têm seus direitos de expressão e de participação, muito mais do que só direitos de proteção e de provisão, conforme consta na Convenção sobre os Direitos da Criança da Organização das Nações Unidas (ONU), que é lei em todos os Estados que a assinaram, incluindo Brasil e Portugal, mas é muito desconhecida. Criança, no conceito da ONU, é todo ser humano menor de 18 anos. Portanto, nós poderíamos dizer: como as crianças de três ou quatro anos vão expressar o que querem? Bom, elas exprimem isso de diferentes maneiras. Eu descobri, quando tive meus próprios filhos, que com um ano elas já nos toureiam de uma forma altamente sofisticada, mas, à medida que vão crescendo, vão intensificando a maneira de interagir, o modo de obter o que desejam e de se expressar. É preciso que haja quem ouça [a criança], mas que não deixe de ser adulto com ela, porque o equívoco muitas vezes é acharmos que devíamos ser como as próprias crianças, até no modo de se vestir, e isso cria grandes enganos nos processos educativos.

$C E \mathcal{E} E$ : Professor, o senhor abordou alguns temas que são muito caros à educomunicação, como o direito à expressão de crianças e jovens. Então aproveitamos a deixa para perguntar o que o senhor poderia nos dizer sobre as pesquisas sobre educomunicação em Portugal.

MP: Em primeiro lugar, não utilizamos o conceito de educomunicação. Tenho sido um defensor do conceito, mas obviamente somos também fruto do nosso contexto. A perspectiva em que desenvolvi essas atividades e fiz pesquisa com as minhas equipes esteve muito centrada nos media. Portanto nós podemos dizer que, desse ponto de vista, estamos inscritos numa abordagem que procura não mais enfatizar a influência da mídia - eu volto a clarificar isso -, mas o modo como ela atua enquanto um agente poderoso de socialização, desde a tenra idade, na sua variedade de expressões, e é apropriada naturalmente de formas diversas e em níveis também diversos, porque, nesse encontro entre a mídia e os mais jovens, ou os usuários em geral, nós temos que ter em conta que há sempre os recursos econômicos, sociais e culturais dos próprios receptores. O significado é tributário desse encontro e dessa relação, e não apenas do fator "influência midiática": é também [tributário] daquilo que os atores sociais introduzem nesse encontro.

O que verificamos é que há desigualdades muitas vezes cavadas e profundas, que vemos até na internet. Eu julgo que hoje, só para dar um exemplo, nós estamos a assistir a um fenômeno que já não é de desigualdade no acesso, porque, praticamente, quanto ao device e à máquina, podemos dizer que quase toda a gente tem acesso - e às vezes até sacrificam outros consumos para poderem ter uma boa versão de um smartphone, por exemplo. Mas o problema é que as desigualdades começam a ser vistas no nível dos usos. Fazemos usos que tiram partido de recursos que existem na internet para dar sentido a uma vida mais feliz, mais significativa. Sobre esse nível, há investigações neste momento que mostram que as desigualdades estão sendo cavadas. É completamente diferente, por exemplo, eu mexer no universo da 
minha rede social, ou de duas ou três redes sociais e mais uma operação e outra que eu faço com o smartphone, ou explorar toda a panóplia de recursos que se podem encontrar, incluindo aquilo que eu próprio posso criar e desenvolver como resposta às solicitações do meio.

$C \mathcal{E}$ E: Aproveitando ainda essa discussão sobre a questão da desigualdade, mas mantendo o tema da pergunta anterior, o senhor poderia falar um pouco mais sobre o papel e a contribuição do jornalismo para a educomunicação, dentro desse ponto de vista que acabamos de discutir?

MP: Eu sou muito sensível a essa questão porque, primeiro, muito do meu contato e da minha experiência com a mídia foi como jornalista. As questões que me levaram a descobrir a mídia e a educomunicação foram precisamente motivadas por questões do jornalismo. Ora, elas hoje estão, por razões acrescidas, ainda mais vivas e mais cruas. Eu julgo que, hoje, mais do que nunca, nós todos temos um grande desafio de fazer sentido do mundo que vivemos. Isso é difícil, porque muitas dimensões não têm sentido ou têm uma multiplicidade de sentidos, de forma que nós precisamos ter bússolas, máquinas de orientação ou GPS que nos guiem na barafunda, que nos digam: "este caminho está demasiado atravancado de trânsito, é melhor ir por ali"; ou que digam simplesmente: "é melhor eu parar e olhar de novo com outro olhar”, por exemplo. Ou procurar fontes alternativas de informação.

De fato, o mundo hoje é um mundo de difícil leitura. Nós, mais velhos, temos algumas referências do passado que até nos permitem classificar fenômenos, organizar o caos - o magma, quase, em forma - da informação em catadupas [jorros] que circulam. Mas, para alguém que seja levado na torrente, é difícil agarrar-se a qualquer coisa e dizer: "alto lá, o que é que está aqui a passar?”. Eu vejo o grande desafio de uma literacia das notícias como um ensaio, uma procura da resposta a esta pergunta: "alto lá, o que é que se passa aqui? Que sentido é que isto tem? Por onde é que as coisas estão a ir? Eu posso continuar nesta corrente sem mais, sem ferramentas, sem instrumentos?". Eu começo, portanto, a colocar a pergunta como [se fosse] um usuário que pode confundir-se e ter dificuldade de, com base naquilo que contata, tomar as decisões que a vida lhe impõe. E ao dizer "o indivíduo", eu adiciono também as comunidades quando tomam suas decisões quanto a seu destino. A coisa é sobretudo dramática quando nós vemos comunidades inteiras eventualmente irem nessa onda, por exemplo, da desinformação, que é um dos maiores desafios de hoje.

Portanto, eu diria que o trabalho que se torna crucial fazer é, em primeiro lugar, perceber como a informação é produzida hoje, quem a produz, que fontes a sustentam, que credibilidade merecem, que elementos quem dá a informação fornece para nós, enquanto usuários, podermos avaliar a fidedignidade da informação que estamos a ter. Isso coloca um desafio, quer aos usuários, quer aos jornalistas e a quem produz; põe a informação a circular. Hoje, para o bem e para o mal, os jornalistas perderam o monopólio da palavra no espaço público e, se assim for, bem podem os jornalistas berrar na praça pública... A realidade tem mais força. Há hoje aquilo que um 
sociólogo português já jubilado [José Madureira Pinto, professor aposentado da Universidade do Porto ${ }^{4}$ chamava de "a multiplicação dos polos de enunciação na sociedade”. Não é que isso esteja concretizado, porque também não é verdade que qualquer um faça isso. Aí estão de novo as desigualdades a funcionar. Isso é um logro, uma conversa que a gente fez um aviso. Dizem assim: "hoje, toda a gente faz e põe informação, ou pode pôr"... Não! Isso depende de recursos e competências que não nascem com as pessoas; portanto, é preciso desenvolvê-las. É um engodo quando nós dizemos que "qualquer um pode fazer", e é importante ter isto em conta. É precisamente porque não é qualquer um que pode fazer que importa a capacitação das pessoas - ou seu empoderamento, se quisermos utilizar um palavrão.

Portanto, eu considero que, da parte dos jornalistas, um dos trabalhos mais importantes de se fazer hoje, do ponto de vista da capacitação das audiências, é ser mais transparente quanto aos processos seguidos para a produção de informação e dar-lhes conta juntamente com o texto ou o conteúdo da informação que veiculam. Enquanto muitos continuam agarrados à ideia da objetividade - que nós sabemos que pode ser um ideal, mas não é possível, porque sempre difundimos a informação e escolhemos o que dizemos a partir de algum ponto ou quadro -, torna-se necessário que eles nos digam, por exemplo, do que estão a dizer: se todos os elementos foram verificados; ou se há elementos que foram verificados em parte e, portanto, eles não têm total certeza daquilo que estão a dizer. Isso é crucial, muitas vezes, por nós dizermos: "isto de fato é grave"; ou então: "ah, o título per se aponta para uma coisa muito grave, nós vamos a ver”. Há aqui muitos bemóis, como se diz na música. Portanto, nós ficamos na dúvida.

O que justamente distingue o trabalho de um jornalista que está vinculado a um código de ética e deontologia é que ele faça esse trabalho suposto no contrato implícito com a sociedade. Mas eu digo mais: ele hoje deve dizer o que fez, com uma espécie de making of da notícia ou da reportagem. Não quer dizer que ele tenha que fazer outra peça - embora comece a haver casos em que aparecem outras peças ao lado -, mas sim dizer como algo ocorreu e onde estiveram os pontos difíceis, os fortes, de quais eles têm certeza... Julgo que é preciso trabalhar esse lado da ética jornalística. Com o meio digital, nota-se que "se abandalhou" a vigilância da ética jornalística - nós utilizamos um bocado essa expressão para dizer que algo se deteriorou muito. Mas a ética hoje é também nossa, porque nós, ou muitos de nós, podemos publicar; nós também precisamos ter a noção de alguns valores dos jornalistas, que tinham o monopólio da palavra. Quer dizer, preciso ter a noção, por exemplo, de que, se eu publico uma imagem de terceiros, posso estar a ofender seus direitos de imagem. Ou, por exemplo, se eu digo uma coisa sem verificar e venho porventura a concluir que ela não é verdade, tenho o dever moral de corrigi-la. São coisas básicas da convivência humana, eu diria, mas ninguém as aprende porque nós continuamos a achar que isso cabe aos jornalistas. Eu defendo que nós - quem se dedica à educação para os media ou à educomunicação - devemos assumir isso como tarefa também.

4. PINTO, José Madureira. A prática da razão sociológica: forçando os limites. In: SEMINÁRIO DE INVESTIGAÇÃO EM MUSEOLOGIA DOS PAIISES DE LIINGUA PORTUGUESA E ESPANHOLA, 1., 2010, Porto. Anais [...]. Porto: Universidade do Porto, 2016. p. 16-26. 
comunicação \& educação • Ano XXIV • número 1 • jan/jun 2019

CE्EE: Com exceção de algumas tentativas, aqui no Brasil ainda não há esse espaço para "destrinchar" o processo de produção do jornalismo. Em Portugal já há?

MP: Surgiu agora uma experiência que está a arrancar com o Sindicato dos Jornalistas, (provavelmente a única profissão no país) que não era capaz de reunir um congresso desde 1998 e o fez, finalmente, no princípio do ano passado. Para meu espanto, um dos temas aprovados por unanimidade na moção final do congresso foi a importância da literacia mediática para as notícias, e [esses profissionais] dispuseram-se a colaborar com o Ministério da Educação para fazer [cursos de] formação com os professores do país inteiro. Pediram uma ajuda aos professores que foram jornalistas e estão a ensinar jornalismo nas universidades, então estou assessorando a direção do sindicato nesse trabalho. Não sei ainda em que isso vai dar, porque vamos começar com um grupo de sete escolas-piloto nas várias regiões de Portugal e depois iremos alargar o projeto para todo o país, com uma bolsa de cerca de 100 jornalistas alinhados na participação do processo.

Eles vão explicar às pessoas o que é o jornalismo e sua importância, as fake news etc. Eu espero, no processo, introduzir uma outra perspectiva que considero muito mais importante, que é ouvir os jovens nas escolas - porque os jornalistas não ouvem e, de novo, são eles que têm a verdade para dizer aos outros, o que eu acho importante. Mas há outras coisas que eles têm de ouvir, senão nada muda. Quer dizer, eles vão continuar convencidos de que podem viver sem as audiências e sem conversar com elas - neste caso, com os jovens e os professores, que serão os interlocutores primeiros, já que depois são os docentes que farão o trabalho nas escolas. Esse processo tem que ocorrer dos dois lados, não só de um. Mas a força toda é tão grande que eu disse: "não vou adiantar nada sem introduzir já a minha questão; vou deixá-los avançar e, depois, nas ações, vou tentar meter outras questões que podem enriquecer o trabalho, pondo-as assim: para enriquecer este trabalho, nós precisamos ouvir mais, saber do que eles [jovens] gostam, do que precisam, por que criticam o jornalismo que têm hoje, por que não ligam para isso, para o que eles ligariam...”. Os jornalistas estão mal e não querem ouvir. Isso é um paradoxo. Eu não admito e não aceito, de um ponto de vista profissional, que eu esteja vendo meu terreno a fugir e não perceba por que ele está a fugir. Diriam "não, não, eu tenho que fazer mais jornalismo"; certo, mas jornalismo para quem, se vocês estão a fugir? Isso é quase básico, mas eu não vejo essa consciência.

$\mathrm{Eu}$ acho que uma das grandes questões introduzidas pela internet é que temos que pôr as coisas de forma circular, de vários lados, e não apenas de um, top-down, mas continuam com a ideia de que eles [os jornalistas] é que têm de dizer quais são as notícias. Eu não tenho que dizer aos jornalistas quais são as notícias. Ora, então eu posso também ter a minha sensibilidade. Eu não lhes retiro o poder de editar, e eles podem escolher fazer sua agenda, mas têm que me ouvir, pois sou um cidadão com direitos. A propósito, há direitos na sociedade, noutros campos, que não se encontram de modo tão fácil no jornalismo. Isso é uma questão grave do futuro do jornalismo. Eu tratei disso 
num texto disponível na internet ${ }^{5}$ - foram as minhas provas de agregação, o exame público feito para ascender a [professor] catedrático, em que temos de apresentar uma lição sobre um tema inovador, ideia que expus já em 2008.

CEEE: Falamos sobre variados termos: educação para os media, educomunicação, media literacy e media education. Esses conceitos apresentam interseções e diferenças. Como o senhor se posiciona relação a eles?

MP: Eu julgo que são conceitos muito importantes porque exprimem realidades e vêm de práticas, de modo que todos expressam à sua maneira uma preocupação que eu considero comum: como os mundos da comunicação e da educação podem dialogar. Isso, por sua vez, tem uma ideia subjacente que eu também imagino ser comum: é importante que dialoguem. Tomando isso como base, eu compreendo que as designações que foram encontradas historicamente para nomear essas preocupações, para que nós as entendêssemos, são facetas, ângulos, aproximações, modos de ver o problema central. Nesse ponto de vista, penso que são uma riqueza e que é bom que haja diferentes designações. Dito isto, também acho - e vi com muita alegria isso ser su-blinhado no II Congresso Internacional de Comunicação e Educação, desde o primeiro dia, pelo professor Ismar de Oliveira Soares - que é importante fazermos esforços no sentido da convergência. Convergência não significa necessariamente que nós reneguemos ou deixemos de lado a perspectiva em que desenvolvemos nosso trabalho até hoje. No meu ponto de vista, significa que nós nos dispomos a dialogar com os outros para enriquecer as nossas próprias práticas. E vejo com muita alegria que, quer do lado da educomunicação, quer do lado da educação para os media ou da literacia mediática, conforme queiramos dizer, há um alargamento de agendas que aponta justamente para o encontro das duas tradições; não para sua fusão - e isso nem me preocupa -, mas para uma maior proximidade.

Nesse sentido, eu vejo que começam a aparecer nas universidades portuguesas temáticas novas. Por exemplo, a literacia mediática ligava-se à terceira idade, porque os idosos vivem muitas vezes uma vida difícil. Em Portugal há problemas: é uma sociedade a envelhecer muito, e muitas vezes não há estruturas de enquadramento e acompanhamento. Geralmente os netos, por causa da crise econômica, emigraram. [Os idosos] querem contatá-los como eles pela internet, e o que os netos fazem é deixar-lhes um guia com três ou quatro operações que podem fazer no smartphone para usar o Skype ou o WhatsApp, e o uso da internet limita-se àquele lado utilitário e imediato. Isso já é algo grande para eles, como é evidente, mas, se se abrisse por pequenos passos esse horizonte das possibilidades da internet, combinando isso com outras formas de animação, incluindo os media, nós poderíamos encontrar um terreno de ação extraordinário - e penso que nesse ponto facilmente nos encontramos com a educomunicação.

Mas há instituições sociais que têm, no mesmo espaço, os mais velhos e os mais novinhos, do jardim infantil, algumas em comunidades pobres pelo menos na Europa isso acontece muito. Então por que não podem se comunicar uns com os outros, os mais velhos e os mais novos? Porque
5. PINTO, Manuel. Digressão sobre a "crise do jornalismo": entre definhamento e re-invenção. Braga: Universidade do Minho, 2008. Disponivel em: http://repositorium. sdum.uminho.pt/handle/1822/40799. Acesso em: 11 mar. 2019. 
os mais novos sabem usar com muito mais facilidade as ferramentas, por exemplo; enquanto os mais velhos têm o saber, a história e uma memória para contar, podendo haver aqui encontros. Eu tenho uma tese de doutoramento neste momento com um italiano (há muitos anos em Portugal) que fez um trabalho de investigação-ação, presente durante um ano numa dessas instituições sociais. É um projeto, quase um currículo, de encontro e trabalho em conjunto entre esses dois polos geracionais, fazendo aquilo que poderíamos chamar um diálogo intergeracional em torno do uso dos media.

Outra área cada vez mais importante é a da saúde, porque cada vez mais a gente toma decisões na vida orientadas pela informação que encontramos. As pessoas "googlam" [e descobrem]: "eu tenho isto, vou procurar o que é preciso fazer”; às vezes, quando vão ao médico, apenas verificam se ele está certo: "oh, o senhor acertou, porque já estive a ver, e é mesmo isso". Quer dizer, isso pode fazer as pessoas correrem graves riscos, porque elas não estão capacitadas com critérios de validação de informação, o que lhes pode custar muito caro. Por exemplo, nós estamos a trabalhar com áreas e problemas que são muitas vezes de vida ou de morte, sem que as pessoas tenham consciência disso, porque acreditam, tal como o meu avô dizia, que "é verdade porque eu vi com estes dois [olhos]"; ou, como os mais ilustrados diziam: "é verdade porque eu li no jornal" ou "se eu vi na televisão, quem vai duvidar que é verdade?". Hoje, a gente faz a mesma operação na internet: "eu vi, estava lá tudo...”. Isto não é verdade, mas não é só. Como é que se desenvolve a comunicação entre os parceiros das instituições públicas de saúde, por exemplo? Numa instituição de saúde pública, entram o pessoal técnico, o médico ou o enfermeiro, os doutores e os usuários... Como comunicam os serviços e como é que se respeita e acolhe os direitos das pessoas? Como elas conhecem seus direitos? Enfim, é um terreno que está por se explorar também, tanto quanto eu conheço. Nós estamos a dar alguns passos com a tese de doutoramento, e poderia dar outros exemplos.

Ao lado da educomunicação, eu tenho visto a questão midiática com certa força, que em alguns momentos não vi, incluindo as questões das fake news e da news literacy, por exemplo. Portanto, eu vejo uma perspectiva de futuro, nesse capítulo, com bastante otimismo, respeitando a diversidade de tradições, apostando no encontro entre as diferenças e aprofundando também epistemologicamente suas preocupações, os grandes objetivos que estão subjacentes nestas várias tradições.

$C \mathcal{E} E$ : Para encerrar, professor, gostaríamos de saber que perspectivas o senhor vê para o estudo e a pesquisa da inter-relação entre comunicação e educação no cenário contemporâneo de retorno a parâmetros conservadores nas propostas educacionais.

MP: Resistência e combate é o que me ocorre dizer, porque, de fato, as políticas neoliberais (e falo agora em particular do caso europeu) estão sendo absolutamente demolidoras em alguns países - não da educomunicação, mas da própria cidadania diante das instituições educativas. Isso é muito grave, mas, em alguns casos - tivemos neste II Congresso exemplos 
disso -, os próprios pais opõem-se a dinâmicas e projetos nas escolas que não sejam meramente centrados nos conteúdos curriculares, porque dizem: "isso é perder tempo, isso é brincadeira; a escola é para ensinar, e nós cremos é em ver as notas no fim". Ora, isso é uma perspectiva altamente redutora da educação, porque as escolas têm que ter uma vocação muito mais completa do seu projeto educativo, que não é apenas o que se passa na sala de aula e mesmo ali nós podemos trabalhar de muitas maneiras -, mas também de uma escola fora das aulas e com toda a educação informal que vai por outros canais, por outras vias.

Portanto, eu devo dizer que estou francamente preocupado. Quanto a isso que digo dos pais, por exemplo, tive já experiências concretas, em projetos europeus nos quais estive envolvido, em que pedimos que as crianças levassem um papel para casa para que os pais as autorizassem a participar do projeto em alguns momentos de aula, e alguns pais recusaram a participação do filho, mesmo quando este quisesse, dizendo: "Eu não só não dou autorização, como critico o professor que está a fazer isto", fazendo queixa do professor à direção da escola. Isso parece-me preocupante. É evidente que nós já vivemos no passado climas muito duros, porventura mais duros do que este; eu não diria próximos, mas quase, de algo que eu recentemente vi surgir outra vez aqui no Brasil, que é a ocorrência de delação e o apelo à denúncia, partindo de dentro das turmas, em relação a conteúdos que eventualmente não agradem a um poder do momento. É evidente que isso é o fim da educação. Se esse tipo de tendência se agravasse e se instalasse, eu julgaria que é perversão, porque faz parte da vida acadêmica a liberdade de pensamento e de expressão. Também é verdade que não faz parte estar a fazer a cabeça das criancinhas ou industriá-las nesta direção ou naquela, porque eu acho que nossa tarefa enquanto formadores é abrir horizontes, e não encerrá-los. Mas não podemos encerrá-los para nenhum lado - se não é para este lado, também não é para aquele. Portanto, eu creio que nós temos que combater e procurar caminhos para resistir a isso, enfim, adaptados às circunstâncias de cada lugar.

\section{REFERÊNCIAS BIBLIOGRÁFICAS}

BRITES, Maria José; PINTO, Manuel. Is there a role for the news industry in improving news literacy? Media Education Research Journal, Leighton Buzzard, v. 7, n. 2, p. 29-47, 2017.

PINTO, José Madureira. A prática da razão sociológica: forçando os limites. In: SEMINÁRIO DE INVESTIGAÇÃO EM MUSEOLOGIA DOS PAÍSES DE LÍNGUA PORTUGUESA E ESPANHOLA, 1., 2010, Porto. Anais [...]. Porto: Universidade do Porto, 2016. p. 16-26.

PINTO, Manuel. Digressão sobre a "crise do jornalismo": entre definhamento e re-invenção. Braga: Universidade do Minho, 2008. Disponível em: http:// repositorium.sdum.uminho.pt/handle/1822/40799. Acesso em: 11 mar. 2019. 